\title{
Toxicity of CuO nanoparticles on the root of Arabidopsis thaliana
}

\author{
Lina $\mathrm{Xu}^{\star^{1}}$, Mou $\mathrm{Yu}^{2}$, Jing Zhao ${ }^{3}$ \\ 1.College of Environmental Science and Engineering, Ocean University of China, \\ Qingdao,Shandong, China
}

2.Sichuan Mianzhu Economic Development Zone,Mianzhu,Sichuan,China

3.Qingdao TianyeGenyuan Real Estate Development Co., Ltd, Qingdao,Shandong, China

Keywords: CuO NPs, Arabidopsis thaliana root, phytotoxicity, oxidative stress, MDA

\begin{abstract}
CuOnanoparticles (NPs) are widely used in commercial applications. With increasing $\mathrm{CuO}$ NPs production, $\mathrm{CuO}$ NPs are likely to present in the environment and pose a potential threaten to ecosystem. In this work, 20 and $50 \mathrm{mg} / \mathrm{L} \mathrm{CuO} \mathrm{NPs} \mathrm{and} 0.15 \mathrm{mg} / \mathrm{L} \mathrm{Cu}^{2+}$ were used to test the toxicity to Arabidopsis thaliana roots. Results showed that CuO NPs can inhibit the root dry weight androot water content at $96 \mathrm{~h}$. ROS and MDA content were increased after exposure to CuO NPs for 96 h. $\mathrm{Cu}^{2+}$ released from CuO NPs exhibited no toxicity on the Arabidopsis thaliana roots.
\end{abstract}

\section{INTRODUCTION}

With the rapid development and versatile application of nanotechnology, a large quantity of nanoparticles (NPs) has been released into the environment. Due to the novel physicochemical properties such as tiny size, large specific surface area and abundant reactive sites on the surface, NPs could be interaction with organisms and pose a potential threaten to organisms even to the whole ecosystem(Handy et al., 2008). CuO NPs as one of the most important engineered NPs has a dual characteristic of metal materials and nano materials (Ivasket al., 2010). CuO NPs are widely used in catalysts, gas sensor, heat transfer fluids, semiconductors, photovoltaic cells, and so on (Wang et al., 2012). Many available data showed that metal oxide NPs could cause inhibition on plant (Dimkpa et al., 2012).Ma et al. (2010) observedthat rare earth oxide nanoparticles, suchas CeO2、 La2O3、Gd2O3、Yb2O3 inhibited the root elongation of plants. Lee et al.(2010) reported that $\mathrm{ZnO}$ NPs had the more toxicity than $\mathrm{Al} 2 \mathrm{O} 3 、 \mathrm{SiO} 2 、 \mathrm{Fe} 3 \mathrm{O} 4$ on the generation of Arabidopsis thaliana, owing to the Zn2+ released from ZnO NPs. However, the toxicity of CuO NPs on the Arabidopsis thaliana rootsis still unknown. The main objective of this study was to investigate the toxicity and the related toxic mechanism of $\mathrm{CuO}$ NPs to Arabidopsis thaliana roots.

\section{MATERIALS AND METHODS}

\subsection{Plant growth and growth inhibition test}

$\mathrm{CuO}$ NPs and $\mathrm{CuO}$ bulk particles (BPs) were purchased from Beijing Nachen S\&T Ltd. Seeds ofArabidopsisecotypes (Col-0) were provided by Prof. Xing at Agricultural University of Hebei, China. The seeds were surface-sterilized by $75 \%$ alcohol and then placed in the agar-containing Murashige and Skoog (MS) medium for germination. After 10-day, the seedlings in the stage of four leaves were moved to dicotyledonous nutrient solution. After additional 3-day culture, the seedlings were moved to distilled water-prepared CuO NPs (20 and $50 \mathrm{mg} / \mathrm{L}$ ), CuO BPs (50 mg/L) suspensions or $\mathrm{Cu} 2+$ ions solution $(0.15 \mathrm{mg} / \mathrm{L})$, respectively. " $0.15 \mathrm{mg} / \mathrm{L}$ ” was selected as the test $\mathrm{Cu} 2+$ concentration based on the dissolution kinetics of CuO NPs in distilled water. The root dry weight was measured by micro balance $(\mathrm{MX} / \mathrm{UMX}$, Mettler Toledo). Root water content $(\%)=$ (M1-M2)/M1, where M1 and M2 are the root fresh weight and root dry weight, respectively.

\subsection{Detection of root ROS and MDA}

The generation of reactive oxygen species (ROS) in roots was measured by the DCF method. In brief, after exposure to $\mathrm{CuO} \mathrm{NPs}$ for $96 \mathrm{~h}$, the ROS in roots was examined with 2', 7'dichlorofluoresceindiacetate (H2DCF-DA, Beyotime, China). The fluorescence intensities were 
determined using a fluorescence microscopy (Olympus IX70). The lipid peroxides was quantized in terms of the Methane Dicarboxylic Aldehyde (MDA) content, the MDA were measured by the thiobarbituric acid reactive substance (TBARS) assay (Vavilin et al., 1998).

\subsection{Statistical analysis}

Statistical analysis was analyzed using a one-way analysis of variance (ANOVA) and compared with LSD test. All treatments included three replicates and standard error was reported $(\mathrm{p}<0.05)$.

\section{RESULTS AND DISCUSSION}

\subsection{Characterization of $\mathrm{CuO}$ NPs and $\mathrm{CuO}$ BPs}

Characterization of $\mathrm{CuO}$ NPs and $\mathrm{CuO}$ BPs were analyzed by transmission electron microscopy (TEM JEM-2100, Japan). The diameters of CuO NPs and CuO BPs were 20-40 nm and $1500 \mathrm{~nm}$ obtained from TEM imaging.

\begin{tabular}{ll} 
Table 1. Characterization of $\mathrm{CuO}$ NPs and CuO BPs \\
\hline Particle & $\begin{array}{l}\text { Diameter } \\
(\mathrm{nm})\end{array}$ \\
\hline $50 \mathrm{mg} / \mathrm{LCuO}$ NPs & $20-40$ \\
$50 \mathrm{mg} / \mathrm{LCuO} \mathrm{BPs}$ & 1500 \\
\hline
\end{tabular}

\subsection{Inhibition of $\mathrm{CuO}$ NPs on root growth}

$\mathrm{CuO} \mathrm{NPs}$ at both $20 \mathrm{mg} / \mathrm{L}$ and $50 \mathrm{mg} / \mathrm{L}$ significantly inhibited the root dry weight of Col-0seedlings compared to the unexposed control, Cu2+ ion $(0.15 \mathrm{mg} / \mathrm{L})$ and $\mathrm{CuO}$ BPs $(50 \mathrm{mg} / \mathrm{L})$ treatments after $96 \mathrm{~h}$ exposure(Figure 1A).The observed growth inhibition of CuO NPs on seedlings was exposure time-dependent. The seedling roots exposed to $50 \mathrm{mg} / \mathrm{LCuO} \mathrm{NPs} \mathrm{for} 96 \mathrm{~h}$, root water content was decreased significantly (Figure 1B).
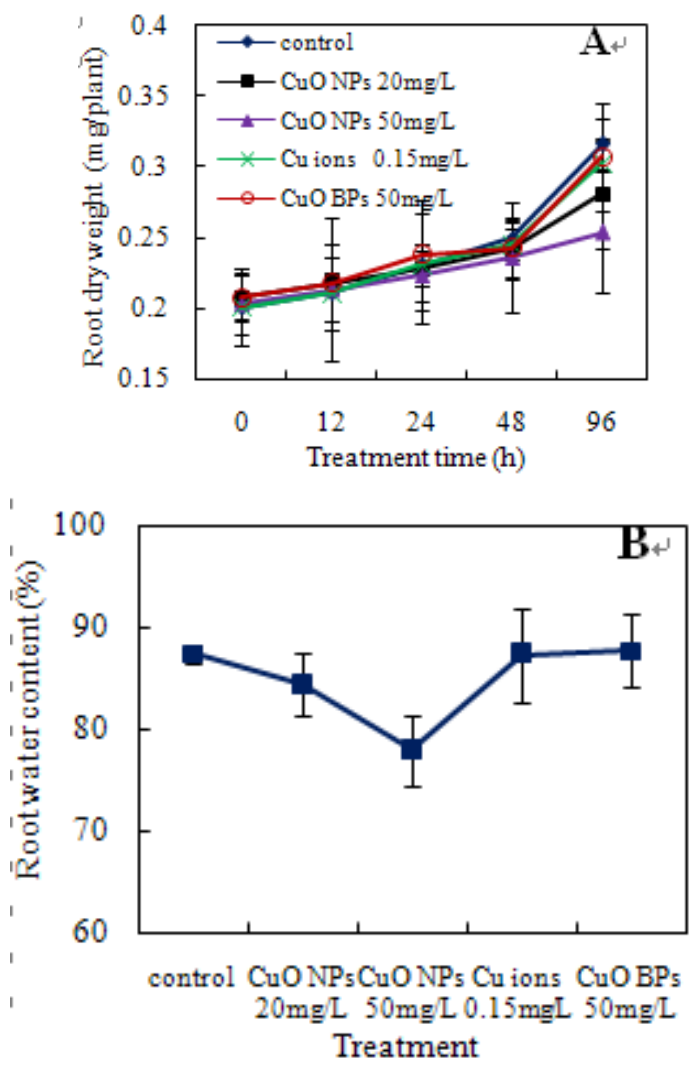

Figure 1. The inhibition of CuO NPs on the root dry weight at different treatment time (A) androot water content at $96 \mathrm{~h}(\mathrm{~B})$ of Col-0 seedlings. Col-0 seedlings were cultured for $96 \mathrm{~h}$ in the distilled water with control, $20 \mathrm{mg} / \mathrm{LCuO} \mathrm{NPs,} 50 \mathrm{mg} / \mathrm{LCuO} \mathrm{NPs,} 0.15 \mathrm{mg} / \mathrm{L} \mathrm{Cu}^{2+}$ ions or $50 \mathrm{mg} / \mathrm{LCuO} \mathrm{BPs}$. 


\subsection{Oxidative stress}

ROS was accumulated after exposed to $\mathrm{CuO}$ NPs for $24 \mathrm{~h}$ and $96 \mathrm{~h}$, The ROS level in Col-0 roots exposure into $\mathrm{CuO}$ NPs showed both time and dose dependent. Exposed to $50 \mathrm{mg} / \mathrm{L} \mathrm{CuO} \mathrm{NPs}$ for $96 \mathrm{~h}$, the ROS level in the roots raised 1.56 times compared with control.

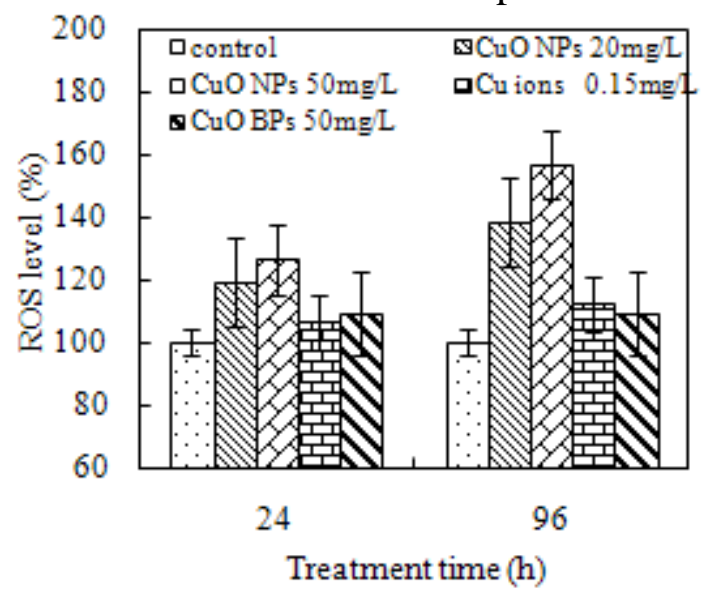

Figure 2. The ROS level in Col-0 roots after exposure to control, $20 \mathrm{mg} / \mathrm{L} \mathrm{CuO} \mathrm{NPs,} 50 \mathrm{mg} / \mathrm{LCuO}$ NPs, $0.15 \mathrm{mg} / \mathrm{L} \mathrm{Cu}^{2+}$ ions and $50 \mathrm{mg} / \mathrm{LCuO}$ BPs for $24 \mathrm{~h}$ and $96 \mathrm{~h}$. For a given treatment time, significant difference among different treatments compared control was marked with “*”.

\subsection{Lipid peroxidation}

Lipid peroxidation in cell membrane caused by oxidative stress could result in the cell damage and even the plant died. As shown in figure 3, there are more MDA contents in roots treated by 20 and $50 \mathrm{mg} / \mathrm{LCuO}$ NPs than treatments without $\mathrm{CuO}$ NPs within $96 \mathrm{~h}$. However, the content of MDA was not significantly increase treated by $\mathrm{Cu2}+$ and $\mathrm{CuO}$ BPs.

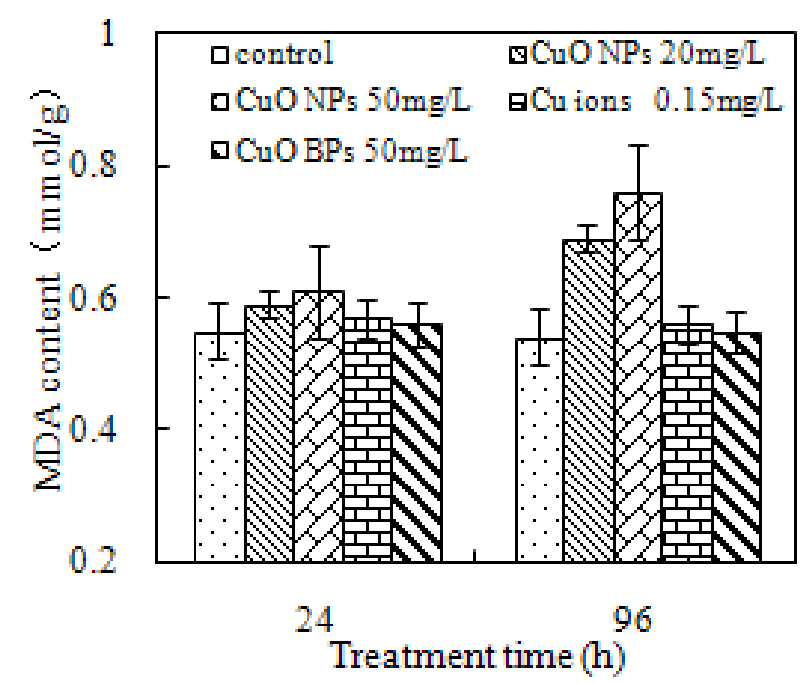

Figure 3. The MDA content in Col-0 roots after exposure to control, $20 \mathrm{mg} / \mathrm{L} \mathrm{CuO} \mathrm{NPs,} 50 \mathrm{mg} / \mathrm{L}$ $\mathrm{CuO}$ NPs, $0.15 \mathrm{mg} / \mathrm{L} \mathrm{Cu}^{2+}$ ions and $50 \mathrm{mg} / \mathrm{LCuO}$ BPs for $24 \mathrm{~h}$ and $96 \mathrm{~h}$. For a given treatment time, significant difference among different treatments compared control was marked with “*”.

\section{CONCLUSIONS}

The results of this study demonstrated that toxicity of CuO NPs to Col-0 roots is time-effect relationship and dose-effect relationship. $\mathrm{CuO} \mathrm{BPsandCu2+}$ released from $\mathrm{CuO}$ NPs exhibited no toxicity on the Arabidopsis thaliana roots. Oxidative stress is responsible for the toxicity of $\mathrm{CuO}$ NPs. 


\section{ACKNOWLEDGEMENT}

This work supported by National Natural Science Foundation of China (No. 41120134004).

\section{REFERENCE}

1. Handy R.D., Qwen, R., Crane, R., The ecotoxicology and chemistry of manufactured nanoparticles. Ecotoxicology, 2008, 17(4): 287-314

2. Ivask, A.; Bondarenko, O.; Jepihhina, N.; Kahru, A. Profiling of the reactive oxygen species-related ecotoxicity of $\mathrm{CuO}, \mathrm{ZnO}, \mathrm{TiO}_{2}$, silver and fullerene nanoparticles using a set of recombinant luminescent Escherichia coli strains: differentiating the impact of particles and solubilised metals. Anal. Bioanal. Chem. 2010, 398, 701-716.

3. Wang, Z.; Xie, X.; Zhao, J.; Liu, X.; Feng, W.; White, J. C.; Xing, B. Xylem- and phloem-based transport of $\mathrm{CuO}$ nanoparticles in maize (Zea mays L.). Environ. Sci. Technol. 2012, 46, 4434-4441.

4. Dimkpa, C. O.; McLean, J. E.; Latta, D. E.; Manangón, E.; Britt, D. W.; Johnson, W. P.; Boyanov, M. I.; Anderson, A. J. CuO and ZnO nanoparticles: phytotoxicity, metal speciation, and induction of oxidative stress in sand-grown wheat. J. Nanopart. Res. 2012, 14, 1-15.

5. Ma Y., Kuang, L., Chai, Z., Effects of rare earth oxide nanoparticles on root elongation of plants. Chemosphere, 2010, 78(3): 273-279

6. Lee, C. W.; Mahendra, S.; Zodrow, K.; Li, D.; Tsai, Y. C.; Braam, J.; Alvarez, P. J. Developmental phytotoxicity of metal oxide nanoparticles to Arabidopsis thaliana. Environ. Toxicol. Chem. 2010, 29, 669-675. 